\title{
An Evaluation of Physical Activity Levels amongst University Employees
}

\author{
Ayazullah Safi1 ${ }^{*}$, Matthew Cole², Adam L. Kelly², Natalie C. Walker ${ }^{2}$ \\ ${ }^{1}$ University of Westminster, London, UK \\ ${ }^{2}$ Birmingham City University, Birmingham, UK \\ Email: *a.safi@westminster.ac.uk
}

How to cite this paper: Safi, A., Cole, M., Kelly, A. L., \& Walker, N. C. (2021). An Evaluation of Physical Activity Levels amongst University Employees. Advances in Physical Education, 11, 158-171.

https://doi.org/10.4236/ape.2021.112012

Received: January 29, 2021

Accepted: March 23, 2021

Published: March 26, 2021

Copyright $\odot 2021$ by author(s) and Scientific Research Publishing Inc. This work is licensed under the Creative Commons Attribution International License (CC BY 4.0).

http://creativecommons.org/licenses/by/4.0/ (c) (i) Open Access

\begin{abstract}
Approximately $60 \%$ of the world's population do not meet the physical activity (PA) guidelines. Physical inactivity is increasing in occupations, with work-related health issues becoming more prevalent. University employees' work in a range of job roles and PA levels in this population is unclear. Thus, this study aimed to evaluate PA levels amongst university employees in a UK Higher Education institution. Four hundred employees (male $=131$, female $=$ 269) partook in this quantitative study and completed an online International Physical Activity Questionnaire Long Form (IPAQ-LF) to assess total moderate to vigorous PA (MVPA) and work-related MVPA. A Mann-Whitney U test examined differences in total MVPA and work-related MVPA between genders and a Kruskal-Wallis $\mathrm{H}$ test examined differences in total MVPA and work related MVPA between job roles. The findings showed that university employees engaged in a median of 330 minutes and 1770 METs of MVPA across all domains of IPAQ-LF. Further, the median time spent in total work PA was 30 minutes and 123 METs. There was a significant difference between genders, as males engaged in 150 minutes more total MVPA compared to females $(p<0.05)$. No significant differences were found in total MVPA and work-related MVPA across job roles $(p>0.05)$. Findings suggest that job role does not affect PA levels within university workplace, although they do propose that males engage in more MVPA compared to females. As a result of the subjective nature of this research, objective research is required to confirm current findings.
\end{abstract}

\section{Keywords}

Employees Physical Activity Levels, Workplace Health and Well-Being, Sedentary Behaviour 


\section{Introduction}

Despite the well-known benefits of physical activity (PA) such as reducing the risk of coronary heart disease, diabetes, obesity, musculoskeletal disorders, anxiety and depression (Church et al., 2011; Griffiths, Mackey, Adamson, \& Pepper, 2012; Van Uffelen et al., 2010; Kelley, Kelley, \& Callahan, 2018; Rebar et al., 2015 ) yet approximately $60 \%$ of the world's population fail to accumulate adequate PA levels (Rentería \& Morris, 2017). The World Health Organisation (WHO) PA guidelines suggest that adults should engage in a minimum of 150 minutes of moderate to vigorously physical activities, alongside undertaking muscle-strengthening exercises twice a week. There are several explanations that may suggest why majority of the adults do not participate in regular PA. For example, contemporary evidence suggests that "time availability" is the primary barrier preventing adults from achieving the recommended guideline (Brown, Volberding, Baghurst, \& Sellers, 2014; Edmunds, Hurst, \& Harvey, 2013; Joseph, Ainsworth, Keller, \& Dodgson, 2015; Leininger, Adams, \& DeBeliso, 2015a). Furthermore, it is the time specifically devoted to "work responsibilities" which are purported to have the biggest detrimental impact upon engagement in regular PA (Bardus, Blake, Lloyd, \& Suzanne Suggs, 2014; da Silva et al., 2017). Previous research reported that adults spent approximately $60 \%-70 \%$ of their waking time in the workplace, with over $75 \%$ of this time spent being sedentary (Clemes et al., 2015; Edge, Cooper, \& Coffey, 2017; Healy, Matthews, Dunstan, Winkler, \& Owen, 2011; Waters et al., 2016). Workplaces, including office-based jobs in particular, involve minimum physical movements during the working days, which may increase the risk of health related diseases. Additionally, physical inactivity and prolonged sitting can negatively affect the circulation and the use of muscles and bones (Dunstan, Howard, Healy, \& Owen, 2012; Smith et al., 2015). From a fiscal point of view, the Confederation of British Industry (CBI) reported that sickness absences cost the UK economy more than $£ 14$ billion a year (CBI, 2016), whilst the Office for National Statistics (ONS) figures for 2017 estimated that 131.2 million working days were lost due to sickness and injury (ONS, 2017).

As a general consensus, previous research suggests that males spend more time engaging in PA compared to females (Becher \& Trowler, 2001; Guthold, Stevens, Riley, \& Bull, 2018; Lindsay, Devine, Sealey, \& Leicht, 2016; Reed et al., 2018). For instance, according to the Centre for Economic and Business Research, $32 \%$ of male and $42 \%$ of female employees were reported as inactive (CEBR, 2015). Furthermore, the ONS revealed that the rates of absences were higher in females compared to elderly and males equivalents in organisations with 500 or more employees (ONS, 2017). Organisations with an average of 250 employees are estimated to make a loss of around $£ 250,000$ annually due to the sickness absence (Wills \& Linneker, 2012). Previous research has shown that the attitude and motivation of males and females towards PA are different. For example, males are generally attracted to physical exertion which positively influences their PA participation, whereas females are more notorious to engage in verbal games, conversation, and socialising (Berenbaum, Martin, Hanish, Briggs, \& Fabes, 2008; 
Hands, Parker, Larkin, Cantell, \& Rose, 2016; Weiss \& Smith, 2002). Therefore, it is important to evaluate the existing PA levels between genders to understand the differences that may occur in their PA levels, thus providing an insight into the higher risk population amongst employees (Guthold et al., 2018).

There is a suggestion that research must focus on PA levels of employees in the workplace who are potentially being overlooked (Jackson, Lewis, Conner, Lawton, \& RC McEachan, 2014). This suggestion has been reiterated by other researchers', who have proposed an evaluation of current PA rates amongst employees from a range of job roles across different workplaces is required (Arundell et al., 2018; Roncancio, Sing, Sadhra \& Carmichael, 2014; Jackson et al., 2014; Lisa Janzen Leininger et al., 2015a; Reed et al., 2018; Reis et al., 2016). Despite these suggestions, there are limited studies that have focused on employees within the education sector; particularly within higher education. There are 162 universities in the UK employing approximately 378,000 members of staff (Dooris, Doherty, \& Orme, 2017). Most of the research focused on university employees' PA levels and sedentary behaviour has classified employees as a homogeneous group. However, due to the cultural differences across faculties, departments, and responsibilities, it is important to recognise that universities have a diverse range of job roles. There is a lack of insight into distinguishing employees across departments and job roles, with current research mainly focussing on academic staff (McEwan, 2013). The different types of job roles may offer different opportunities to engage in PA due to the level of autonomy or flexibility in working conditions. For instance, academics are reported to have more autonomy or flexibility to engage in PA in the workplace compared to those in administration or support services (Becher \& Trowler, 2001; McEwan, 2013). Thus, it is important to consider these differences when exploring PA levels.

This study aimed to evaluate PA rates amongst university employees based on gender and job role. Drawing from the existing literature available, it was hypothesised that male employees would participate in significantly more PA than females (Guthold et al., 2018; Lindsay et al., 2016; Olney et al., 2018). In addition, it was hypothesised that university staff employed in more active roles (e.g., academic and estate) would participate in significantly more PA compared to office-based roles (e.g., administration and support services) (McEwan, 2013).

\section{Methods}

\subsection{Participants and Procedures}

Following institutional ethical approval, an invitation email was sent to all university employees $(n=2143)$ inviting them to complete an online survey. Four hundred $(19 \%)$ employees' (male $=131$, female $=269$ ) subsequently completed the online survey. The online survey comprised of the International Physical activity Questionnaire Long-Form (IPAQ-LF) (IPAQ, 2002) to record participants' engagement in PA over the previous seven days. Previous research has applied the IPAQ-LF and reported that it is the most valid and reliable instru- 
ment for measuring PA levels across a range of domains (Craig et al., 2003; Gustafson \& Rhodes, 2006; Haskell et al., 2007). Furthermore, recent studies have compared the validity of the IPAQ-LF to objective tools (e.g., pedometers) and concluded that it showed an acceptable level of reliability in measuring PA patterns in adults (Cleland, Ferguson, Ellis, \& Hunter, 2018; Hagströmer, Oja, \& Sjöström, 2006; Wanner et al., 2016; Wrzesińska, Lipert, Urzędowicz, \& Pawlick$i, 2018)$. Additionally, previous research has also recognised that the IPAQ-LF is the most suitable and cost-effective tool to assess PA in the workplace (Helou et al., 2018; Päivärinne, Kautiainen, Heinonen, \& Kiviranta, 2018).

Participants were recruited from six job roles to ensure a diverse representation of the workforce: 1) Academics included teaching and researching staff ( $n=$ $190)$; 2) Administration Services included day to day service staff $(n=98)$; 3$)$ Marketing and Communication included staff promoting the university $(n=$ $34)$; 4) Library included staff maintaining the libraries $(n=35)$; 5) Estate included staff managing the building $(n=20)$; and, 6) Information Technology (IT) included staff engaging in computer and technical duties $(n=23)$. Participants recorded their engagement in different types of PA, including: 1) walking, 2) moderate-intensity, and 3) vigorous-intensity exercise. These PA types were recorded as part of their work, transportation, domestic and yard, and leisure time activities.

\subsection{Statistical Analysis}

As per the IPAQ-LF guidelines, all responses to the duration were converted from hours into minutes and METs. All statistical tests were conducted using IBM SPSS Statistics for Windows version 24.0 software (IBM Corporation, Armonk, NY, USA). Data are presented as median, total range, mean, and standard deviation (SD) for overall total MVPA across the four domains of the IPAQ-LF for both male, females and job roles. A Shapiro-Wilk's test was used for data not normally distributed $(p<0.05)$. The data between males and females were not normally distributed as evaluated by the Shapiro-Wilk's test $(p<0.05)$. Therefore, a non-parametric Mann Whitney $U$ test was used to analyse the minutes and METs for total MVPA, total work PA, and work MVPA, for both males and females. The data between jobs roles were also not normally distributed as assessed by the Shapiro-Wilk's test $(p<0.05)$. Thus, the Kruskal-Wallis $\mathrm{H}$ test was conducted to compare the differences between job roles. In all instances, the level of significance for analysis was set at $p<0.05$.

\section{Results}

Results revealed that males participated in more total MVPA, across all four domains of the IPAQ-LF, compared to females (see Table 1). The median for total MVPA revealed males participated in significantly more in total MVPA (450 minutes and 2490 METs) compared to females (300 minutes and 1440 METs; $\mathrm{U}=13,421.000, \mathrm{z}=-3.870, p<0.001, \mathrm{U}=13,042.500 . \mathrm{z}=-4.219, p<$ 
0.001). Furthermore, there was no significant difference between males (40 minutes, 132 METs) and females (30 minutes, 120 METs) for the median total work PA ( $\mathrm{U}=16.702 .000, \mathrm{z}=-0.871, p=0.384, \mathrm{U}=16.819 \mathrm{z}=-0.760, p=$ 0.447). Additionally, there was no significant difference between males and females for work MVPA $(\mathrm{U}=17.563 .000 \mathrm{z}=-0.060, p=0.952$ and $\mathrm{U}=17,524.000$ $\mathrm{z}=0.101, p=0.919)$.

With regards to job roles, Estate staff participated in more total MVPA (363 minutes and 1785 METs), followed by Library staff (360 minutes and 1950 METs), compared to other job roles (see Table 2). There was no significant differences between job roles in total MVPA $\left(\chi^{2}(5)=2.212, p=0.819, \chi^{2}(5)=\right.$ 1.914, $p=0.861$ ). Furthermore, Marketing and Communication staff revealed to be spending more time in the work total PA (45 minutes and 182 METs), followed by Academic staff (40 minutes and 132 METs), with Administration Services

Table 1. Descriptive statistics of total MVPA, total work PA, and work MVPA for males and females in minutes and METs throughout the week.

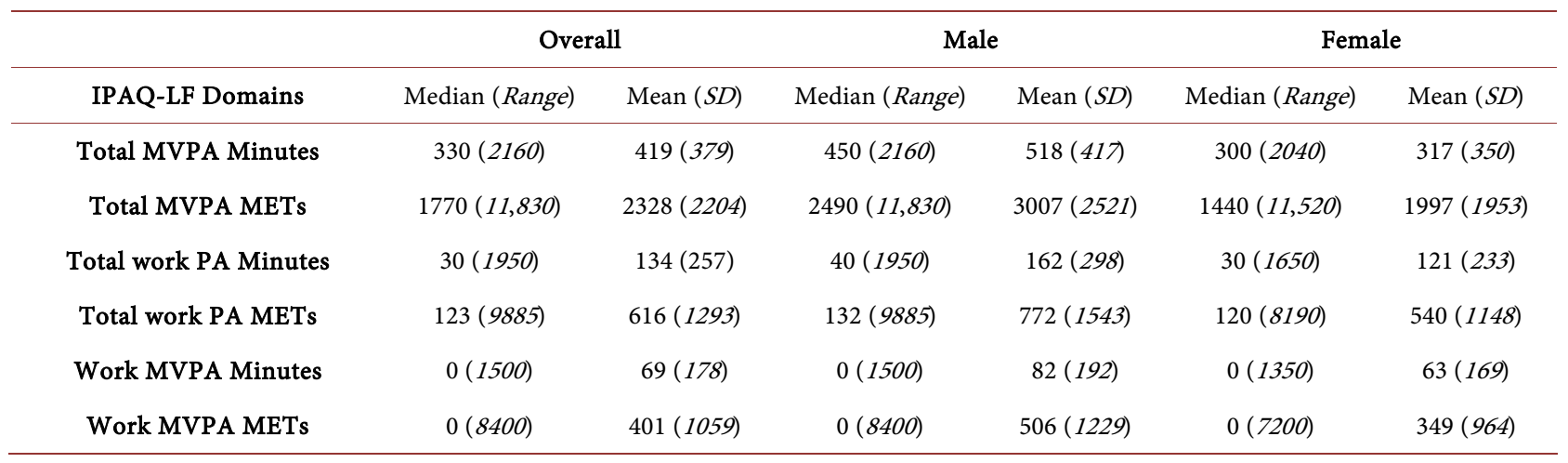

Table 2. Descriptive statistics of total MVPA, total work PA, and work MVPA between job roles in minutes and METs across the week.

\begin{tabular}{|c|c|c|c|c|c|c|c|c|c|c|c|c|}
\hline \multirow[b]{2}{*}{ IPAQ-LF Domains } & \multicolumn{2}{|c|}{ Academics } & \multicolumn{2}{|c|}{$\begin{array}{l}\text { Administration } \\
\text { Services }\end{array}$} & \multicolumn{2}{|c|}{$\begin{array}{l}\text { Marketing and } \\
\text { Communicating }\end{array}$} & \multicolumn{2}{|c|}{ Library } & \multicolumn{2}{|c|}{ Estate } & \multicolumn{2}{|c|}{$\begin{array}{l}\text { Information } \\
\text { Technology }\end{array}$} \\
\hline & $\begin{array}{l}\text { Median } \\
\text { (Range) }\end{array}$ & $\begin{array}{c}\text { Mean } \\
(S D)\end{array}$ & $\begin{array}{l}\text { Median } \\
\text { (Range) }\end{array}$ & $\begin{array}{c}\text { Mean } \\
(S D)\end{array}$ & $\begin{array}{l}\text { Median } \\
\text { (Range) }\end{array}$ & $\begin{array}{c}\text { Mean } \\
(S D)\end{array}$ & $\begin{array}{l}\text { Median } \\
\text { (Range) }\end{array}$ & $\begin{array}{c}\text { Mean } \\
(S D)\end{array}$ & $\begin{array}{c}\text { Median } \\
(\text { Rang) }\end{array}$ & $\begin{array}{c}\text { Mean } \\
(S D)\end{array}$ & $\begin{array}{c}\text { Median } \\
\text { (Rang) }\end{array}$ & $\begin{array}{c}\text { Mean } \\
(S D)\end{array}$ \\
\hline Total MVPA Minutes & $\begin{array}{c}330 \\
(2160)\end{array}$ & $\begin{array}{l}425 \\
(389)\end{array}$ & $\begin{array}{c}333 \\
(2040)\end{array}$ & $\begin{array}{c}415 \\
(384)\end{array}$ & $\begin{array}{c}325 \\
(1515)\end{array}$ & $\begin{array}{c}385 \\
(350)\end{array}$ & $\begin{array}{c}360 \\
(1860)\end{array}$ & $\begin{array}{c}460 \\
(386)\end{array}$ & $\begin{array}{c}363 \\
(1500)\end{array}$ & $\begin{array}{l}456 \\
(388)\end{array}$ & $\begin{array}{c}300 \\
(1195)\end{array}$ & $\begin{array}{c}338 \\
(311)\end{array}$ \\
\hline Total MVPA METs & $\begin{array}{c}1808 \\
(11,830)\end{array}$ & $\begin{array}{c}2411 \\
(2274)\end{array}$ & $\begin{array}{c}1700 \\
(11,570)\end{array}$ & $\begin{array}{l}2324 \\
(226)\end{array}$ & $\begin{array}{c}1595 \\
(9320)\end{array}$ & $\begin{array}{c}2216 \\
(2124)\end{array}$ & $\begin{array}{c}1950 \\
(10,680)\end{array}$ & $\begin{array}{c}2373 \\
(2084)\end{array}$ & $\begin{array}{c}1785 \\
(8430)\end{array}$ & $\begin{array}{c}2314 \\
(2135)\end{array}$ & $\begin{array}{c}1150 \\
(7710)\end{array}$ & $\begin{array}{c}1771 \\
(1783)\end{array}$ \\
\hline Total work PA Minutes & $\begin{array}{c}40 \\
(1950)\end{array}$ & $\begin{array}{c}133 \\
(251)\end{array}$ & $\begin{array}{c}25 \\
(1650)\end{array}$ & $\begin{array}{c}117 \\
(246)\end{array}$ & $\begin{array}{c}45 \\
(1320)\end{array}$ & $\begin{array}{c}191 \\
(350)\end{array}$ & $\begin{array}{c}30 \\
(400)\end{array}$ & $\begin{array}{c}91 \\
(121)\end{array}$ & $\begin{array}{c}30 \\
(900)\end{array}$ & $\begin{array}{c}165 \\
(242)\end{array}$ & $\begin{array}{c}30 \\
(1320)\end{array}$ & $\begin{array}{l}178 \\
(344)\end{array}$ \\
\hline Total work PA METs & $\begin{array}{c}132 \\
(9885)\end{array}$ & $\begin{array}{c}634 \\
(1329)\end{array}$ & $\begin{array}{c}83 \\
(8190)\end{array}$ & $\begin{array}{c}516 \\
(118)\end{array}$ & $\begin{array}{c}182 \\
(7398)\end{array}$ & $\begin{array}{c}883 \\
(1758)\end{array}$ & $\begin{array}{c}165 \\
(1460)\end{array}$ & $\begin{array}{c}381 \\
(489)\end{array}$ & $\begin{array}{c}110 \\
(2970)\end{array}$ & $\begin{array}{l}678 \\
(979)\end{array}$ & $\begin{array}{c}99 \\
(7260)\end{array}$ & $\begin{array}{c}805 \\
(1692)\end{array}$ \\
\hline Work MVPA Minutes & $\begin{array}{c}0 \\
(1500)\end{array}$ & $\begin{array}{c}71 \\
(184)\end{array}$ & $\begin{array}{c}0 \\
(1350)\end{array}$ & $\begin{array}{c}63 \\
(174)\end{array}$ & $\begin{array}{c}0 \\
(0)\end{array}$ & $\begin{array}{c}93 \\
(240)\end{array}$ & $\begin{array}{c}0 \\
(360)\end{array}$ & $\begin{array}{c}45 \\
(87)\end{array}$ & $\begin{array}{c}0 \\
(450)\end{array}$ & $\begin{array}{c}50 \\
(118)\end{array}$ & $\begin{array}{c}0 \\
(720)\end{array}$ & $\begin{array}{c}95 \\
(195)\end{array}$ \\
\hline Work MVPA METs & $\begin{array}{c}0 \\
(8400)\end{array}$ & $\begin{array}{c}431 \\
(1127)\end{array}$ & $\begin{array}{c}0 \\
(7200)\end{array}$ & $\begin{array}{c}336 \\
(957)\end{array}$ & $\begin{array}{l}1200 \\
(7200)\end{array}$ & $\begin{array}{l}560 \\
(144)\end{array}$ & $\begin{array}{c}0 \\
(1440)\end{array}$ & $\begin{array}{c}230 \\
(380)\end{array}$ & $\begin{array}{c}0 \\
(2520)\end{array}$ & $\begin{array}{l}300 \\
(716)\end{array}$ & $\begin{array}{c}0 \\
(5280)\end{array}$ & $\begin{array}{c}532 \\
(1215)\end{array}$ \\
\hline
\end{tabular}


spending the least (25 minutes and 83 METs), compared to other job roles. There was no significant difference between job roles for median $\left(\chi^{2}(5)=1.913\right.$, $\left.p=0.861, \chi^{2}(5)=2.053, p=0.842\right)$. Additionally, there was no significant difference between job roles for work-related $\operatorname{MVPA}\left(\chi^{2}(5)=2.067, p=0.840, \chi^{2}\right.$ (5) $=2.392, p=0.793)$.

\section{Discussion}

To the authors' knowledge, this is one of the few studies to evaluate PA rates of university employees. Specifically, the aim of this study was to examine the PA differences between gender and job roles within and outside of the workplace. The key findings revealed that on average university employees spent $330 \mathrm{mi}-$ nutes and 1770 METs engaged in total MVPA throughout the week. The findings also suggest that this population spent a decreased amount of time being active at work across the week, with males on average engaging in 40 minutes of PA (132 METs) and females engaging in 30 minutes of PA (121 METs). Moreover, findings show the decreased amount of time employees spent being active at work is also evident in job roles.

When compared to the WHO PA guidelines, the university employees in this study exceeded over double the minimum recommended minutes. This finding displays the combination of PA that includes all four categories of the IPAQ -LF, without making a distinction between the workplace. Thus, despite the higher levels of PA, employees are spending approximately $77 \%$ of their daily working time inactive in the workplace (Thorp et al., 2012). As such, it is evident that the typical workplace may be restrictive towards PA due to the diminishing amount of PA being conducted throughout the week. Previous research have suggested that the lack of PA opportunities in the workplace could have adverse effects on mental health and well-being (Ma, Ma, Wang, \& Kim, 2020; Zhu et al., 2020). In addition, if working environment provides opportunities for PA engagement this may yield different results in terms of employees' health and well-being. Thus, it is important for key stakeholders to consider ways in which universities can support their employees to obtain greater PA levels during working hours.

The most common PA conducted at work was walking which is considered a light form of exercise. Interestingly, the median work MVPA showed to be zero minutes and METs. As a result, there appears to be a distinct lack of MVPA being conducted during work by the majority of employees in this university setting. Additionally, this indicates that the mean data is skewed by a few participants, as demonstrated by a median of zero. Therefore, the majority of employees conduct very little or no work MVPA at all. This is also likely due to the requirements for university employment being sedentary-based roles (e.g., working at a desk), which results in MVPA not being an active requirement (Fountaine, Piacentini, \& Liguori, 2014). Therefore, it is suggested that appropriate interventions are implemented to enhance MVPA within the university workplace, to ensure employees are provided with opportunities to be active 
during working hours. For example, some of the commonly applied and existing interventions focus on walking using step counters (Chomistek et al., 2017), encouraging stair use (Engelen, Gale, Chau, \& Bauman, 2018), and active travel to work (e.g., cycle to work scheme or walk to work) (Audrey et al., 2019; Bauman, Crane, Drayton, \& Titze, 2017) to improve employees PA engagement in the workplace (Ryde \& Brown, 2017).

The differences between genders demonstrated that male participants were spending more time engaging in total MVPA and total work PA compared to females. Current findings align with previous research, suggesting that males are more active than females (Guthold et al., 2018; Olney et al., 2018; Page, Cooper, Griew, Davis, \& Hillsdon, 2009). The difference for MVPA could be a result of gender choices when engaging in PA activities that may involve high intensity. The interaction between gender and culture could have also affected the total MVPA results, which this study did not consider. Historically females have engaged in lower levels of PA, especially from ethnic minority groups, which could explain the difference observed in this study (Guthold et al., 2018; Lindsay et al., 2016; Olney et al., 2018). Previous research also suggested that social support within the workplace, such as moving together in a walking group outdoor, was highly valued by female employees (Morris, Guell, \& Pollard, 2019). However, both male and female participants reported being the least active at work, which is in agreement with existing literature (Alkhajah et al., 2012; Chau et al., 2013; Thivel et al., 2018). As such, considering a gender-specific approach to encouraging greater PA levels at work may be a more fruitful approach rather than implementing solitary interventions.

With regards to job role, the lowest number of minutes for total work PA was recorded by the Administration Services. This may be an expected finding due to the nature of this role, whereby staff are required to spend majority of their day at desks. When focussing on the nature of job role it was hypothesised that Estates staff would engage in a higher amount of PA since their job requirements are considered physically demanding. For example, previous research revealed that staff within maintenance roles, such as manual and physical labour, generally elicit higher PA levels compared to employees within professional or administrative (Schofield, Badlands, \& Oliver, 2005; Steele \& Mummery, 2003). However, in contrast with previous research (Fountaine et al., 2014), current findings rejected this hypothesis, revealing that Estates spent a comparable amount of active time to that of Library and IT staff. Thus, these findings could reflect that the desk-based responsibilities, as well as the services provided through the campus, by both Library and IT staff.

The nature of Marketing and Communication staff involves cross-campus communications, venue scouting, and actively promoting university through events. Thus, the increased amount of walking and PA resulted in the highest for total work PA (45 minutes, $182 \mathrm{METs}$ ) compared to other job roles. Another unpredicted result was total work PA for Academic staff (40 minutes, 132 METs). 
For example, previous research has suggested that Academic staff spend a higher amount of working time sedentary (Lindsay et al., 2016). However, the current study demonstrated that Academic staff are more likely to conduct workplace PA compared to other job roles. This may be conducted through teaching practical sessions, walking to and during lectures, and perhaps are commuting across campuses. Further research is required to explore how different jobs roles are exposed to different types of PA during their working hours, to ensure appropriate interventions are developed to match the needs of the diverse university employee population.

With workplaces becoming more sedentary, it has resulted in the reduction of PA (Ashe, 2012; Cooper \& Barton, 2016; Fountaine et al., 2014; Green, 2017; Leininger, Adams, Debeliso, \& Orozco, 2015b). The enhancement of technology, increased work demands, and policies requiring employees to be at the desk may be contributing factors to the reduction of PA in the workplace. For example, research has demonstrated that the occupational structure from physical to machinery, has contributed to the decline in PA (Engbers, van Poppel, Paw, \& van Mechelen, 2005). This is evident in the total work PA when compared to the other IPAQ-LF domains examined in this study. Previous studies evaluated PA levels across settings and reported that employees are spending the least amount of time engaging in PA at work, particularly office-based employees (Alkhajah et al., 2012; Ashe, 2012; Chau et al., 2013; Gilson et al., 2009; Hu, Chen, \& Cheng, 2016; Thivel et al., 2018), which is illustrated in the current findings for Administration Services. Previous research recommended a goal setting strategy effective for improving PA in office staff such as walking up and down the stairs, standing for the period of a phone call, and walking during a break (McGuckin, Sealey, \& Barnett, 2017). The PA of Administration Services could improve if the workplace provides flexibility such as a longer lunch break or short period of multiple breaks throughout the working days as this will provide an opportunity for PA engagement. Thus, future research is encouraged to explore the effectiveness of such strategies; based on both gender and job role.

\section{Conclusion}

In contrast to existing literature, current study found university employees exceeded the recommended PA guidelines. Moreover, it was revealed that employees spent the least amount of time being active in the workplace. In addition, gender differences were also demonstrated, whereby male employees were significantly more active compared to females across total MVPA and total work PA. Since employees were least active in the workplace, it could be suggested workplace PA and health interventions could offer useful outcomes. The self-reported methodology allowed an insight into the differences reported across gender and various job roles. For instance, male employees were significantly more active than females. Further, Marketing and Communications and Academic staff spent more time engaged in work-related PA compared to Ad- 
ministration Services, Library, Estate, and IT staff. Thus, this suggests PA and health-related interventions may require a gender and role-specific approach. Nevertheless, the current study offers a benchmark for employees within a university based in the UK, whilst providing recommendations for future research within this particular domain.

Despite revealing impactful results surrounding PA levels of university employees, this study is not without limitations. First, data was collected via IPAQ-LF and the use of self-reported methods was subject to human error, such as under or overestimations (Adams et al., 2005; Bauman et al., 2009). Social desirability may have also affected the results discovered which could be reduced through the use of alternative PA monitors such as accelerometers. Second, the gender discrepancy in PA may have also been a result of socio-cultural differences amongst gender, which was not a consideration during this study. Thus, future research should consider the impact of socio-cultural factors, such as ethnicity and socioeconomic status, to offer a broader representation of university employees. Finally, future research is required to validate the present findings from a range of working disciplines. Thus, further research should gain an insight into the employees' PA levels and sedentary behaviour through an objective measure, such as accelerometer.

\section{Acknowledgements}

This study is part of the on-going PhD research that is one of the 50 STEAM Scholars at Birmingham City University and it is funded as part of the Universi-

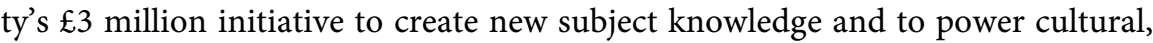
societal and economic improvements. The authors would like to thank all the participants in this study for their participation. The authors would also like to thank Fatema Khatun for her support in this study.

\section{Conflicts of Interest}

The authors declare no conflicts of interest regarding the publication of this paper.

\section{References}

Adams, S. A., Matthews, C. E., Ebbeling, C. B., Moore, C. G., Cunningham, J. E., Fulton, J., \& Hebert, J. R. (2005). The Effect of Social Desirability and Social Approval on Self-Reports of Physical Activity. American Journal of Epidemiology, 161, 389-398. https://doi.org/10.1093/aje/kwi054

Alkhajah, T. A., Reeves, M. M., Eakin, E. G., Winkler, E. A., Owen, N., \& Healy, G. N. (2012). Sit-Stand Workstations: A Pilot Intervention to Reduce Office Sitting Time. American Journal of Preventive Medicine, 43, 298-303.

https://doi.org/10.1016/j.amepre.2012.05.027

Arundell, L., Sudholz, B., Teychenne, M., Salmon, J., Hayward, B., Healy, G., \& Timperio, A. (2018). The Impact of Activity Based Working (ABW) on Workplace Activity, Eating Behaviours, Productivity, and Satisfaction. International Journal of Environmental Research and Public Health, 15, 1005. https://doi.org/10.3390/ijerph15051005 
Ashe, M. C. (2012). Physical Activity and Workplace Sedentary Behaviour. Toronto: University of Toronto Press Incorporated. https://doi.org/10.3138/ptc.64.1.ge1

Audrey, S., Fisher, H., Cooper, A., Gaunt, D., Metcalfe, C., Garfield, K., Rodgers, S. et al. (2019). A Workplace-Based Intervention to Increase Levels of Daily Physical Activity: The Travel to Work Cluster RCT. Public Health Research, 7, 1-158. https://doi.org/10.3310/phr07110

Bardus, M., Blake, H., Lloyd, S., \& Suzanne Suggs, L. (2014). Reasons for Participating and Not Participating in a e-Health Workplace Physical Activity Intervention: A Qualitative Analysis. International Journal of Workplace Health Management, 7, 229-246. https://doi.org/10.1108/IJWHM-11-2013-0040

Bauman, A., Ainsworth, B. E., Bull, F., Craig, C. L., Hagströmer, M., Sallis, J. F., Sjöström, M. et al. (2009). Progress and Pitfalls in the Use of the International Physical Activity Questionnaire (IPAQ) for Adult Physical Activity Surveillance. Journal of Physical Activity and Health, 6, S5-S8. https://doi.org/10.1123/jpah.6.s1.s5

Bauman, A., Crane, M., Drayton, B. A., \& Titze, S. (2017). The Unrealised Potential of Bike Share Schemes to Influence Population Physical Activity Levels-A Narrative Review. Preventive Medicine, 103, S7-S14. https://doi.org/10.1016/j.ypmed.2017.02.015

Becher, T., \& Trowler, P. (2001). Academic Tribes and Territories: Intellectual Enquiry and the Culture of Disciplines. London: McGraw-Hill Education (UK).

Berenbaum, S. A., Martin, C. L., Hanish, L. D., Briggs, P. T., \& Fabes, R. A. (2008). Sex Differences in Children's Play. In J. Becker, K. Berkeley, N. Geary, \& E. Hampton (Eds.), Sex Differences in the Brain: From Genes to Behavior (pp. 275-290). Oxford: Oxford University Press. https://doi.org/10.1093/acprof:oso/9780195311587.003.0014

Brown, C. T., Volberding, J., Baghurst, T., \& Sellers, J. (2014). Faculty/Staff Perceptions of a Free Campus Fitness Facility. International Journal of Workplace Health Management, 7, 156-170. https://doi.org/10.1108/IJWHM-05-2013-0020

CBI (2016). Health: The Key to Productivity? Sickness Absence Survey 2016.

CEBR (2015). The Economic Cost of Physical Inactivity in Europe (p. 83).

Chau, J. Y., Grunseit, A. C., Chey, T., Stamatakis, E., Brown, W. J., Matthews, C. E., van der Ploeg, H. P. et al. (2013). Daily Sitting Time and All-Cause Mortality: A Meta-Analysis. PLoS ONE, 8, e80000. https://doi.org/10.1371/journal.pone.0080000

Chomistek, A. K., Yuan, C., Matthews, C. E., Troiano, R. P., Bowles, H. R., Rood, J., Bassett Jr., D. R. et al. (2017). Physical Activity Assessment with the ActiGraph GT3X and Doubly Labeled Water. Medicine \& Science in Sports \& Exercise, 49, 1935. https://doi.org/10.1249/MSS.0000000000001299

Church, T. S., Thomas, D. M., Tudor-Locke, C., Katzmarzyk, P. T., Earnest, C. P., Rodarte, R. Q., Bouchard, C. et al. (2011). Trends over 5 Decades in US Occupation-Related Physical Activity and Their Associations with Obesity. PLoS ONE, 6, e19657. https://doi.org/10.1371/journal.pone.0019657

Cleland, C., Ferguson, S., Ellis, G., \& Hunter, R. F. (2018). Validity of the International Physical Activity Questionnaire (IPAQ) for Assessing Moderate-to-Vigorous Physical Activity and Sedentary Behaviour of Older Adults in the United Kingdom. BMC Medical Research Methodology, 18, 176. https://doi.org/10.1186/s12874-018-0642-3

Clemes, S. A., Houdmont, J., Munir, F., Wilson, K., Kerr, R., \& Addley, K. (2015). Descriptive Epidemiology of Domain-Specific Sitting in Working Adults: The Stormont Study. Journal of Public Health, 38, 53-60. https://doi.org/10.1093/pubmed/fdu114

Cooper, K., \& Barton, G. C. (2016). An Exploration of Physical Activity and Wellbeing in University Employees. Perspectives in Public Health, 136, 152-160. 
https://doi.org/10.1177/1757913915593103

Craig, C. L., Marshall, A. L., Sjöström, M., Bauman, A. E., Booth, M. L., Ainsworth, B. E., Sallis, J. F. et al. (2003). International Physical Activity Questionnaire: 12-Country Reliability and Validity. Medicine \& Science in Sports \& Exercise, 35, 1381-1395. https://doi.org/10.1249/01.MSS.0000078924.61453.FB

da Silva, I. C. M., Mielke, G. I., Bertoldi, A. D., Arrais, P., Luiza, V. L., Mengue, S. S., \& Hallal, P. C. (2017). Overall and Leisure-Time Physical Activity among Brazilian Adults: National Survey Based-On the Global Physical Activity Questionnaire. Journal of Physical Activity and Health, 15, 212-218.

Dooris, M., Doherty, S., \& Orme, J. (2017). The Application of Salutogenesis in Universities (pp. 237-245). In The Handbook of Salutogenesis. Berlin: Springer.

Dunstan, D. W., Howard, B., Healy, G. N., \& Owen, N. (2012). Too Much Sitting-A Health Hazard. Diabetes Research and Clinical Practice, 97, 368-376. https://doi.org/10.1016/j.diabres.2012.05.020

Edge, C. E., Cooper, A. M., \& Coffey, M. (2017). Barriers and Facilitators to Extended Working Lives in Europe: A Gender Focus. Public Health Reviews, 38, Article No. 2. https://doi.org/10.1186/s40985-017-0053-8

Edmunds, S., Hurst, L., \& Harvey, K. (2013). Physical Activity Barriers in the Workplace: An Exploration of Factors Contributing to Non-Participation in a UK Workplace Physical Activity Intervention. International Journal of Workplace Health Management, 6, 227-240. https://doi.org/10.1108/IJWHM-11-2010-0040

Engbers, L. H., van Poppel, M. N., Paw, M. J. C. A., \& van Mechelen, W. (2005). Worksite Health Promotion Programs with Environmental Changes: A Systematic Review. American Journal of Preventive Medicine, 29, 61-70. https://doi.org/10.1016/j.amepre.2005.03.001

Engelen, L., Gale, J., Chau, J. Y., \& Bauman, A. (2018). Are Motivational Signs to Increase Stair Use a Thing of the Past? A Multi-Building Study. Health Promotion Journal of Australia, 28, 178-184. https://doi.org/10.1071/HE16107

Fountaine, C. J., Piacentini, M., \& Liguori, G. A. (2014). Occupational Sitting and Physical Activity among University Employees. International Journal of Exercise Science, 7, 295-301.

Gilson, N. D., Puig-Ribera, A., McKenna, J., Brown, W. J., Burton, N. W., \& Cooke, C. B. (2009). Do Walking Strategies to Increase Physical Activity Reduce Reported Sitting in Workplaces: A Randomized Control Trial. International Journal of Behavioral Nutrition and Physical Activity, 6, 43. https://doi.org/10.1186/1479-5868-6-43

Green, N. (2017). Evaluating Feedback on Workplace Physical Inactivity with Wellness Employees.

Griffiths, K. L., Mackey, M. G., Adamson, B. J., \& Pepper, K. L. (2012). Prevalence and Risk Factors for Musculoskeletal Symptoms with Computer Based Work across Occupations. Work, 42, 533-541. https://doi.org/10.3233/WOR-2012-1396

Gustafson, S. L., \& Rhodes, R. E. (2006). Parental Correlates of Physical Activity in Children and Early Adolescents. Sports Medicine, 36, 79-97. https://doi.org/10.2165/00007256-200636010-00006

Guthold, R., Stevens, G. A., Riley, L. M., \& Bull, F. C. (2018). Worldwide Trends in Insufficient Physical Activity from 2001 to 2016: A Pooled Analysis of 358 Population-Based Surveys with 1.9 Million Participants. The Lancet Global Health, 6, e1077-e1086. https://doi.org/10.1016/S2214-109X(18)30357-7

Hagströmer, M., Oja, P., \& Sjöström, M. (2006). The International Physical Activity 
Questionnaire (IPAQ): A Study of Concurrent and Construct Validity. Public Health Nutrition, 9, 755-762. https://doi.org/10.1079/PHN2005898

Hands, B. P., Parker, H., Larkin, D., Cantell, M., \& Rose, E. (2016). Male and Female Differences in Health Benefits Derived from Physical Activity: Implications for Exercise Prescription. Journal of Women's Health, Issues and Care, 5, Article ID: 1000238. https://doi.org/10.4172/2325-9795.1000238

Haskell, W. L., Lee, I.-M., Pate, R. R., Powell, K. E., Blair, S. N., Franklin, B. A., Bauman, A. et al. (2007). Physical Activity and Public Health. Updated Recommendation for Adults from the American College of Sports Medicine and the American Heart Association. Circulation, 116, 1081-1093. https://doi.org/10.1249/mss.0b013e3180616b27

Healy, G. N., Matthews, C. E., Dunstan, D. W., Winkler, E. A., \& Owen, N. (2011). Sedentary Time and Cardio-Metabolic Biomarkers in US Adults: NHANES 2003-06. European Heart Journal, 32, 590-597. https://doi.org/10.1093/eurheartj/ehq451

Helou, K., El Helou, N., Mahfouz, M., Mahfouz, Y., Salameh, P., \& Harmouche-Karaki, M. (2018). Validity and Reliability of an Adapted Arabic Version of the Long International Physical Activity Questionnaire. BMC Public Health, 18, 49. https://doi.org/10.1186/s12889-017-4599-7

Hu, N.-C., Chen, J.-D., \& Cheng, T.-J. (2016). The Associations between Long Working Hours, Physical Inactivity, and Burnout. Journal of Occupational and Environmental Medicine, 58, 514-518. https://doi.org/10.1097/JOM.0000000000000715

IPAQ (2002). International Physical Activity Questionnaire Long Version.

Jackson, C., Lewis, K., Conner, M., Lawton, R., \& RC McEachan, R. (2014). Are Incremental Changes in Physical Activity and Sedentary Behaviours Associated with Improved Employee Health? A 12-Month Prospective Study in Five Organisations. International Journal of Workplace Health Management, 7, 16-39. https://doi.org/10.1108/IJWHM-03-2013-0013

Joseph, R. P., Ainsworth, B. E., Keller, C., \& Dodgson, J. E. (2015). Barriers to Physical Activity among African American Women: An Integrative Review of the Literature. Women \& Health, 55, 679-699. https://doi.org/10.1080/03630242.2015.1039184

Kelley, G. A., Kelley, K. S., \& Callahan, L. F. (2018). Community-Deliverable Exercise and Anxiety in Adults with Arthritis and Other Rheumatic Diseases: A Systematic Review with Meta-Analysis of Randomised Controlled Trials. BMJ Open, 8, e019138. https://doi.org/10.1136/bmjopen-2017-019138

Leininger, L. J., Adams, K. J., \& DeBeliso, M. (2015a). Differences in Health Promotion Program Participation, Barriers and Physical Activity among Faculty, Staff and Administration at a University Worksite. International Journal of Workplace Health Management, 8, 246-255. https://doi.org/10.1108/IJWHM-10-2014-0045

Leininger, L. J., Adams, K. J., Debeliso, M., \& Orozco, B. Z. (2015b). Differences in Participation in University Worksite Health Promotion Programs and Physical Activity between Faculty, Staff and Administration. Medicine \& Science in Sports \& Exercise, 47, 391-392. https://doi.org/10.1249/01.mss.0000477496.43360.6e

Lindsay, D. B., Devine, S., Sealey, R. M., \& Leicht, A. S. (2016). Time Kinetics of Physical Activity, Sitting, and Quality of Life Measures within a Regional Workplace: A Cross-Sectional Analysis. BMC Public Health, 16, 786.

https://doi.org/10.1186/s12889-016-3487-x

Ma, J., Ma, D., Wang, Q., \& Kim, H. (2020). The Correlation between Sedentary Behavior by Time Period and Physical Activity and Health Indicators among Japanese Workers. Exercise Medicine, 3, 7. https://doi.org/10.26644/em.2019.007 
McEwan, M. (2013). Investigating Academic Cultural Differences in an International Classroom.

McGuckin, T., Sealey, R., \& Barnett, F. (2017). Goal-Setting Intervention to Reduce Occupational Sedentary Behaviour.

Morris, S., Guell, C., \& Pollard, T. M. (2019). Group Walking as a "Lifeline": Understanding the Place of Outdoor Walking Groups in Women's Lives. Social Science \& Medicine, 238, Article ID: 112489. https://doi.org/10.1016/j.socscimed.2019.112489

Olney, N., Wertz, T., LaPorta, Z., Mora, A., Serbas, J., \& Astorino, T. A. (2018). Comparison of Acute Physiological and Psychological Responses between Moderate-Intensity Continuous Exercise and Three Regimes of High-Intensity Interval Training. The Journal of Strength \& Conditioning Research, 32, 2130-2138.

https://doi.org/10.1519/JSC.0000000000002154

ONS (2017). Sickness Absence Falls to the Lowest Rate on Record.

Page, A. S., Cooper, A. R., Griew, P., Davis, L., \& Hillsdon, M. (2009). Independent Mobility in Relation to Weekday and Weekend Physical Activity in Children Aged 10-11 Years: The PEACH Project. International Journal of Behavioral Nutrition and Physical Activity, 6, 2. https://doi.org/10.1186/1479-5868-6-2

Päivärinne, V., Kautiainen, H., Heinonen, A., \& Kiviranta, I. (2018). Relations between Subdomains of Physical Activity, Sedentary Lifestyle, and Quality of Life in Young Adult Men. Scandinavian Journal of Medicine \& Science in Sports, 28, 1389-1396.

https://doi.org/10.1111/sms.13003

Rebar, A. L., Stanton, R., Geard, D., Short, C., Duncan, M. J., \& Vandelanotte, C. (2015). A Meta-Analysis of the Effect of Physical Activity on Depression and Anxiety in Non-Clinical Adult Populations. Health Psychology Review, 9, 366-378. https://doi.org/10.1080/17437199.2015.1022901

Reed, J. L., Prince, S. A., Pipe, A. L., Attallah, S., Adamo, K. B., Tulloch, H. E., Reid, R. D. et al. (2018). Influence of the Workplace on Physical Activity and Cardiometabolic Health: Results of the Multi-Centre Cross-Sectional Champlain Nurses' Study. International Journal of Nursing Studies, 81, 49-60. https://doi.org/10.1016/j.ijnurstu.2018.02.001

Reis, R. S., Salvo, D., Ogilvie, D., Lambert, E. V., Goenka, S., Brownson, R. C., \& Committee, L. P. A. S. E. (2016). Scaling Up Physical Activity Interventions Worldwide: Stepping Up to Larger and Smarter Approaches to Get People Moving. The Lancet, 388, 1337-1348. https://doi.org/10.1016/S0140-6736(16)30728-0

Rentería, J., \& Morris, L. (2017). Knowledge about Feeding and Practicing Physical Activity as Protective Factors of Overweight and Obesity in Students of Official Schools in the Municipality of Sopó. Obesity Research-Open Journal, 4, 24-31.

https://doi.org/10.17140/OROJ-4-130

Roncancio, M., Sing, M., Sadhra, S., \& Carmichael, F. (2014). Workplace Wellbeing Programmes and Their Impact on Employees and Their Employing Organizations: $A$ Scooping Review of the Evidence Base (p. 59).

Ryde, G., \& Brown, H. (2017). Physical Activity and Workplace Wellbeing. In The Routledge Companion to Wellbeing at Work (pp. 298-313). London: Routledge. https://doi.org/10.4324/9781315665979-21

Schofield, G., Badlands, H., \& Oliver, M. (2005). Objectively-Measured Physical Activity in New Zealand Workers. Journal of Science and Medicine in Sport, 8, 143-151. https://doi.org/10.1016/S1440-2440(05)80005-2

Smith, L., Hamer, M., Ucci, M., Marmot, A., Gardner, B., Sawyer, A., Fisher, A. et al. (2015). Weekday and Weekend Patterns of Objectively Measured Sitting, Standing, and 
Stepping in a Sample of Office-Based Workers: The Active Buildings Study. BMC Public Health, 15, 9. https://doi.org/10.1186/s12889-014-1338-1

Steele, R., \& Mummery, K. (2003). Occupational Physical Activity across Occupational Categories. Journal of Science and Medicine in Sport, 6, 398-407.

https://doi.org/10.1016/S1440-2440(03)80266-9

Thivel, D., Tremblay, A., Genin, P. M., Panahi, S., Rivière, D., \& Duclos, M. (2018). Physical Activity, Inactivity, and Sedentary Behaviors: Definitions and Implications in Occupational Health. Frontiers in Public Health, 6, 288.

https://doi.org/10.3389/fpubh.2018.00288

Thorp, A. A., Healy, G. N., Winkler, E., Clark, B. K., Gardiner, P. A., Owen, N., \& Dunstan, D. W. (2012). Prolonged Sedentary Time and Physical Activity in Workplace and Non-Work Contexts: A Cross-Sectional Study of Office, Customer Service and Call Centre Employees. International Journal of Behavioral Nutrition and Physical Activity, 9, 128. https://doi.org/10.1186/1479-5868-9-128

Van Uffelen, J. G., Wong, J., Chau, J. Y., van der Ploeg, H. P., Riphagen, I., Gilson, N. D., Clark, B. K. et al. (2010). Occupational Sitting and Health Risks: A Systematic Review. American Journal of Preventive Medicine, 39, 379-388. https://doi.org/10.1016/j.amepre.2010.05.024

Wanner, M., Probst-Hensch, N., Kriemler, S., Meier, F., Autenrieth, C., \& Martin, B. W. (2016). Validation of the Long International Physical Activity Questionnaire: Influence of Age and Language Region. Preventive Medicine Reports, 3, 250-256. https://doi.org/10.1016/j.pmedr.2016.03.003

Waters, C. N., Ling, E. P., Chu, A. H., Ng, S. H., Chia, A., Lim, Y. W., \& Müller-Riemenschneider, F. (2016). Assessing and Understanding Sedentary Behaviour in Office-Based Working Adults: A Mixed-Method Approach. BMC Public Health, 16, 360. https://doi.org/10.1186/s12889-016-3023-Z

Weiss, M. R., \& Smith, A. L. (2002). Friendship Quality in Youth Sport: Relationship to Age, Gender, and Motivation Variables. Journal of Sport and Exercise Psychology, 24, 420-437. https://doi.org/10.1123/jsep.24.4.420

Wills, J., \& Linneker, B. (2012). The Costs and Benefits of the London Living Wage. London: Queen Mary University of London.

Wrzesińska, M., Lipert, A., Urzędowicz, B., \& Pawlicki, L. (2018). Self-Reported Physical Activity Using International Physical Activity Questionnaire in Adolescents and Young Adults with Visual Impairment. Disability and Health Journal, 11, 20-30. https://doi.org/10.1016/j.dhjo.2017.05.001

Zhu, X., Yoshikawa, A., Qiu, L., Lu, Z., Lee, C., \& Ory, M. (2020). Healthy Workplaces, Active Employees: A Systematic Literature Review on Impacts of Workplace Environments on Employees' Physical Activity and Sedentary Behavior. Building and Environment, 168, Article ID: 106455. https://doi.org/10.1016/j.buildenv.2019.106455 